\title{
Cardiac hydatid cysts
}

\author{
D. S. G I B SON
}

From the Royal Hobart Hospital, Hobart, Tasmania

There is an increasing number of reports in the literature of cases of primary echinococcosis of the heart which have been treated surgically. Prior to 1932, when Long performed the first successful operation, these cysts were nearly always diagnosed in the post-mortem room. Until 1947 only four successful cases had been reported. Since that time there have been another 42 cases in the world, of which all but seven have been reported as cured.

The following are two cases successfully treated by operation.

\section{CASE REPORTS}

CASE 1 Mrs. B. M.S. aged 23 years was referred to the Thoracic Surgical Clinic of the Royal Hobart Hospital on 18 April 1961 for investigation of a lesion seen in a plain radiograph of the chest (Fig. 1) which had been taken when she had complained of pains in the breasts. This radiograph showed a calcified shadow at the apex of the left ventricle.

She had no complaints other than those related to the breasts; her general health was good; she had a normal exercise tolerance and had no cough.

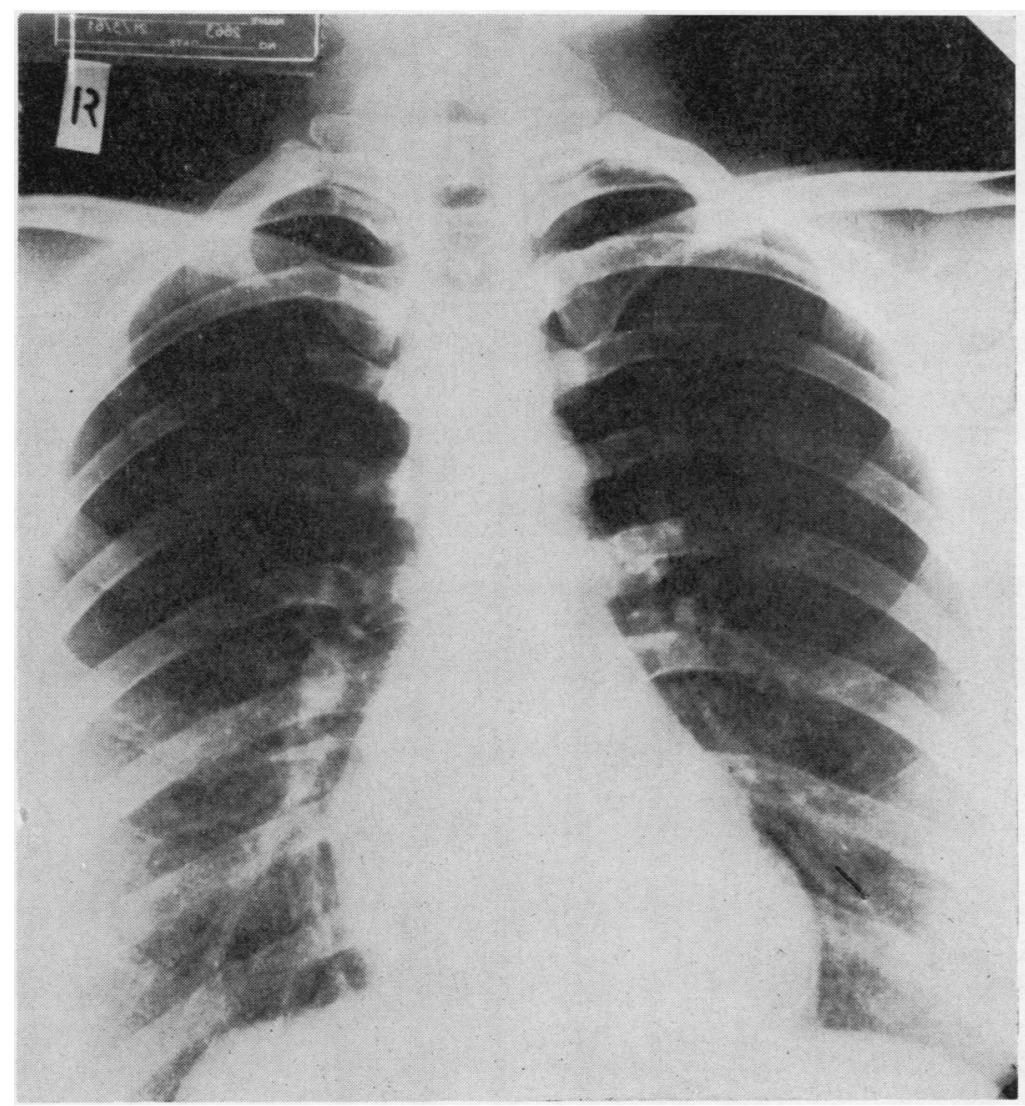

FIG. 1. Case 1. The calcified rim can be seen at the apex of the heart. 
In the past she had had a series of operations for multiple hydatid cysts, starting three years previously when she was first admitted to hospital with a pelvic abscess. When the posterior fornix of the vagina was opened to drain this abscess many hydatid cysts were found.

Six days later a laparotomy revealed multiple hydatid cysts in the greater omentum, multiple hydatid cysts in the pelvis adherent to the uterus, large multilocular hydatid cysts almost replacing the right lobe of the liver (one of which had burst), and free scolices in the peritoneal cavity.

A series of operations were performed during the next 12 months, during which she had the omentum, uterus, tubes, and ovaries removed, and the liver hydatid drained; these operations eventually resulted in an apparent cure of the lesions in the abdominal cavity.

The patient had lived her childhood in a small town in the middle of sheep-rearing country.

Physical examination revealed a fit woman. The pulse was regular and of good volume; the blood pressure was $130 / 65 \mathrm{~mm}$. Hg. The heart was not enlarged clinically and no abnormal sounds could be heard. The chest moved well with respiration and the breath sounds were normal. No mass or viscus could be felt through the very scarred abdominal wall.

Radiographs of the chest and tomograms of the left ventricle showed crescentic calcified shadows over the apex of the heart.

A diagnosis of cardiac hydatid was made; the Casoni test was positive.

An electrocardiogram (E.C.G.) suggested a lesion of the anterior wall of the heart over the septum.

Blood examination revealed a haemoglobin of $13.4 \mathrm{~g}$. $/ 100 \mathrm{ml}$. The white cells numbered 7,500 , and there was no eosinophilia. Liver-function tests and serum electrolytes were normal.

Thoracotomy was performed on 15 May 1961. A left antero-lateral thoracotomy was made through the lower border of the fifth rib. The pleural cavity was

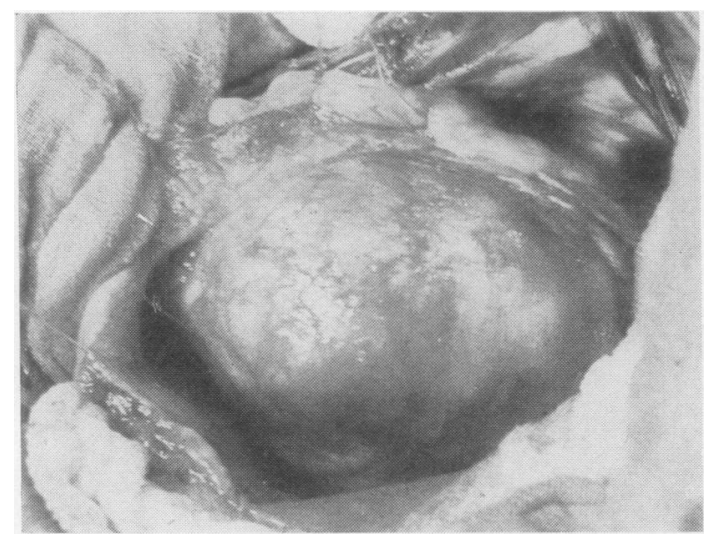

FIG. 2. Case 1. Photograph of the apex of the left ventricle showing the cystic swelling $3 \mathrm{~cm}$. in diameter. free and no lesion could be felt in the left lung. The pericardium was opened from the apex to the region of the left atrial appendage anterior to the phrenic $\underline{\underline{G}}$ nerve, and the flaps were turned back. The pericardial $\frac{\bar{\omega}}{7}$ cavity was obliterated by many fine adhesions which $\mathbb{D}$ were divided by blunt and sharp dissection. There was a hydatid cyst in the wall of the left ventricle, at the $\infty$ true apex, whose surface on the pericardium was $\overrightarrow{0}$ $3 \mathrm{~cm}$. in diameter (Fig. 2). A wide-bore needle attached to the sucker was inserted into the cyst, but only a $\vec{\omega}$ small amount of fluid was obtained. The cyst was opened, and inspissated and calcareous material was $\vec{x}$ removed. The inside of the cyst was curetted. The $\vec{\sim}$ inner wall of the cavity appeared to be a second cyst, but on opening this it was found to be the inner layer of the first cyst, and the incision had opened $\vec{G}$ into the cavity of the ventricle with resulting haemor- $\vec{O}$ rhage (Fig. 3). Haemostasis was secured by placing mattress sutures through the inner layer of the cyst and then closing the outer layer with continuous atraumatic silk, leaving blood within the adventitia of the cyst. The pericardium was approximated with one $\stackrel{ }{\supset}$ suture, leaving the lower part open for drainage. The $\vec{\bullet}$ chest wall was closed with an intercostal drain to an underwater seal. ful.

The immediate post-operative course was unevent-

In June 1961 the patient had an epileptiform fit, but investigation revealed no abnormality in the central nervous system.

In January 1962 she was readmitted with intercostal neuralgia, which settled with physiotherapy.

On this occasion a radiograph of the chest was normal. The E.C.G. was normal. The white cells? numbered 6,600 with $7 \%$ eosinophils. She has remained well since.

CASE 2 Mr. L. W. was admitted to the Royal Hobart Hospital on 3 August 1960 for investigation of black-o outs and allergic skin reactions. He was aged 30 yearsand was a small orchardist and mixed farmer.

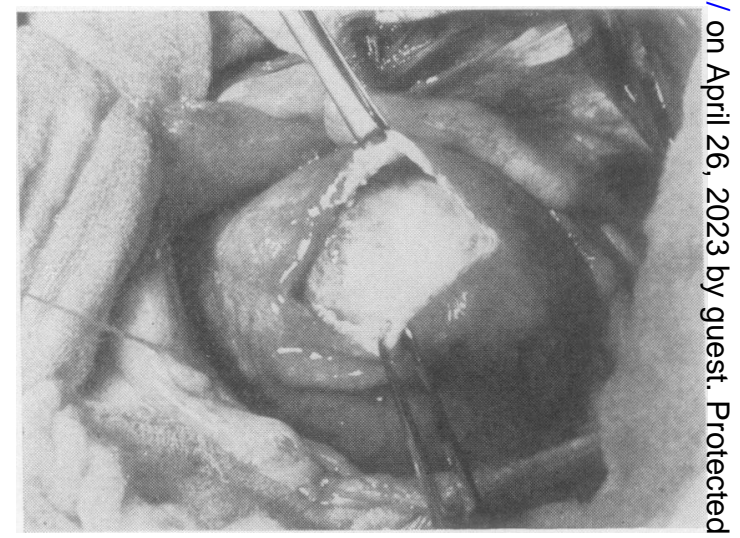

FIG. 3. Case 1. The inside of the cyst cavity in the wall of the left ventricle. 


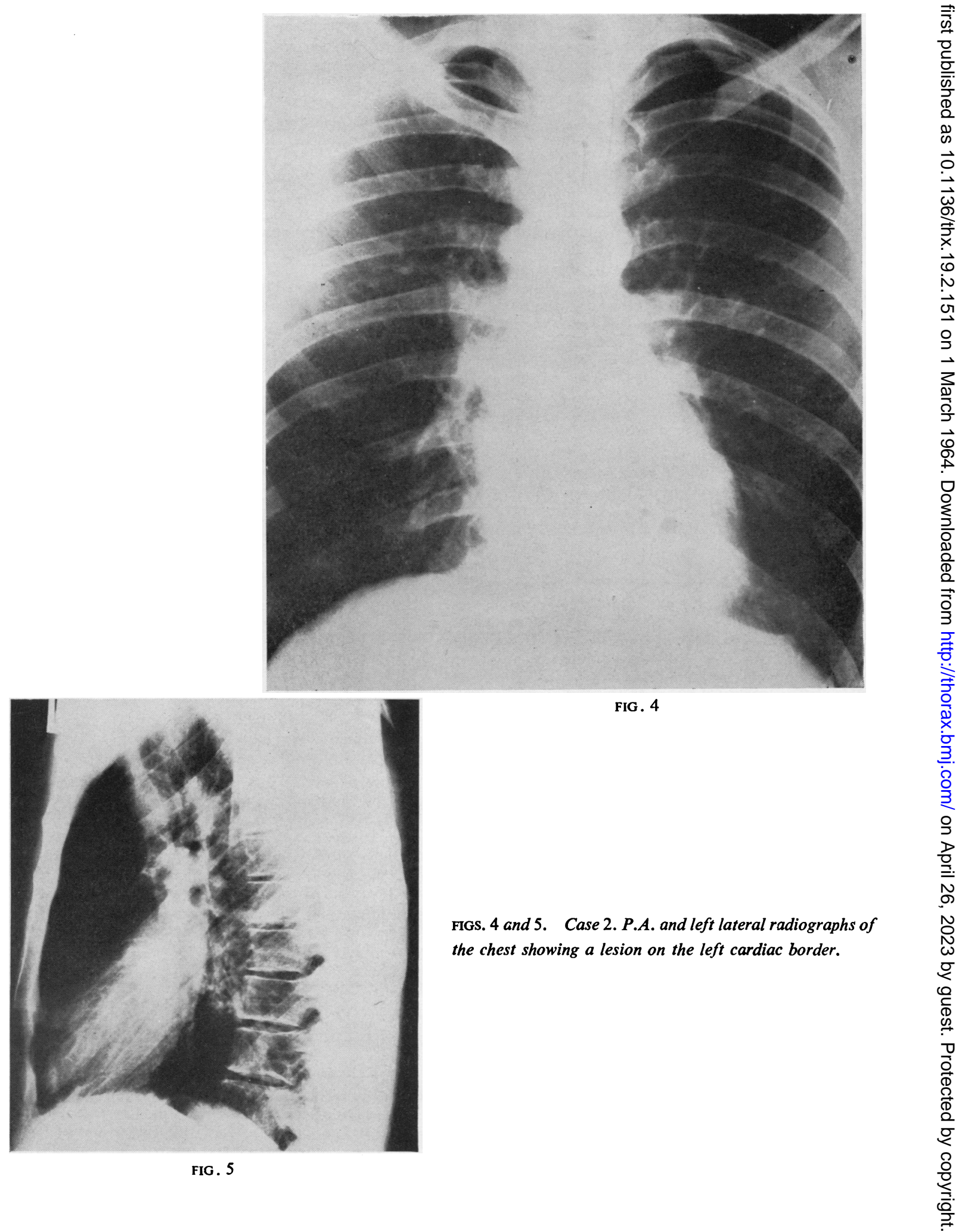


During the past 18 months he had had three attacks of itchy skin rashes followed by blackouts; each attack had been worse than the previous one. The attacks usually came on after a day's activity in the bush. He had awoken at night and found that he was swollen all over the abdomen, chest, lips, face, and hands; the swelling was not lumpy or red. The swelling was accompanied by intense 'crawling' itchiness and also a feeling of heat. The swelling and itchiness subsided after 10 to 15 minutes, and this was followed by vomiting which lasted up to two hours and was followed by a sudden loss of consciousness.

The loss of consciousness lasted five minutes, half an hour, and two and a half hours, respectively, in the three attacks. After the third attack he felt drowsy and confused for two days. After regaining consciousness on each occasion he had a headache all the next day. He had no dyspnoea and his general health was good. He lives on a farm and often has to go into rough country.

There was nothing relevant in his past or family history.

Physical examination revealed a fit man whose pulse was regular and of good volume.

The blood pressure was $135 / 90 \mathrm{~mm}$. $\mathrm{Hg}$. The heart was not enlarged clinically and sounds were normal. No abnormality could be found in the chest or abdomen.

A blood examination showed: $\mathrm{Hb} 17.6 \mathrm{~g} . / 100 \mathrm{ml}$; white cells 9,700 per c.mm. with $30 \%$ neutrophils, $43 \%$ lymphocytes, $1 \%$ monocytes, and $26 \%$ eosinophils.

A plain radiograph of the chest showed an opacity in the left cardiac border (Figs. 4 and 5). Screening and tomograms showed that the lesion was continuous with the heart and that it pulsated. The radiologist thought that this was more in keeping with an aneurysm than with a hydatid.

The patient was referred to the thoracic surgical clinic on 5 August 1960 before any investigations other than a straight radiograph had been performed. Bronchoscopy the next day failed to reveal any abnormality.

A Casoni test was positive.

A radiograph of the liver area on 12 August 1960 showed no abnormality, and the patient was discharged from the medical ward and asked to return in one month to the thoracic surgical clinic.

$\mathrm{He}$ did not return, but was re-referred 15 months later with the diagnosis of cardiac hydatid after further tomograms of the heart had been taken.

He was readmitted to hospital on 8 November 1961 for further investigation and treatment. In the previous 15 months he had remained well and had had no further attacks. Physical examination remained the same.

A left postero-lateral thoracotomy was performed on 15 November 1961 through the lower border of the fifth rib.

An irregular mass was seen within the pericardium high up in line with the phrenic nerve. The pericardial cavity was obliterated by filmy adhesions with
50 to 60 small cysts scattered throughout the cavity but mostly concentrated near the apex of the ventricle.

These small cysts were picked out until the pericardial cavity was clear as far as could be ascertained. There was a cyst in the pericardium about $1 \frac{1}{2} \mathrm{~cm}$. in diameter just over the apex of the left ventricle, and this was excised together with the associated pericardium.

There was a multilocular cystic mass $4 \mathrm{~cm}$. long and $3 \mathrm{~cm}$. broad in the atrioventricular groove containing 20 to 30 daughter cysts. This had pushed the coronary artery upwards and invaded both the atrial and the ventricular wall with the left atrial appendage overlying it.

Firm adhesions binding the pericardium to the main cyst in the atrioventricular groove could not be divided so a circular incision was made in the pericardium around this after dissecting off the phrenic nerve.

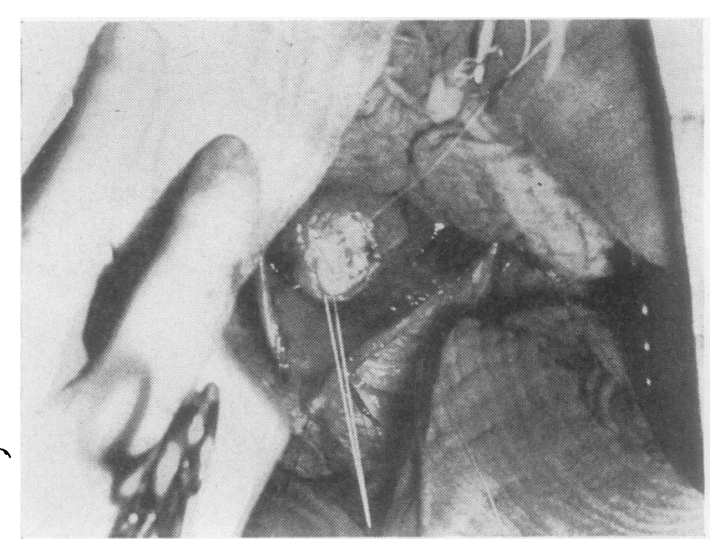

FIG. 6. Case 2. Multiple daughter cysts in the cavity in the atrioventricular groove.

The cyst cavity was opened, a needle was inserted into the cysts and the fluid aspirated (Fig. 6). Multiple small cysts were removed until the cavity was clear. when it was swabbed out with $5 \%$ formalin. Part of the adventitia with adherent pericardium was excised and the edges were sewn together. The pericardium was left widely open and the chest wall was closed with intercostal underwater drainage.

The post-operative course was uneventful, but a plain radiograph of the chest before discharge showed a further rounded shadow on the right side of the superior mediastinum.

He was discharged well on 28 November 1961.

He was readmitted on 13 July 1962 for further investigation and treatment of the lesion on the right side.

Radiographs on 16 July 1962 showed the lesion in the right mediastinum to be persistent (Fig. 7).

Haematological examination still showed an eosinophilia of $32 \%$ out of a total white cell count of 9,400 . The blood chemistry was normal and an E.C.G. 


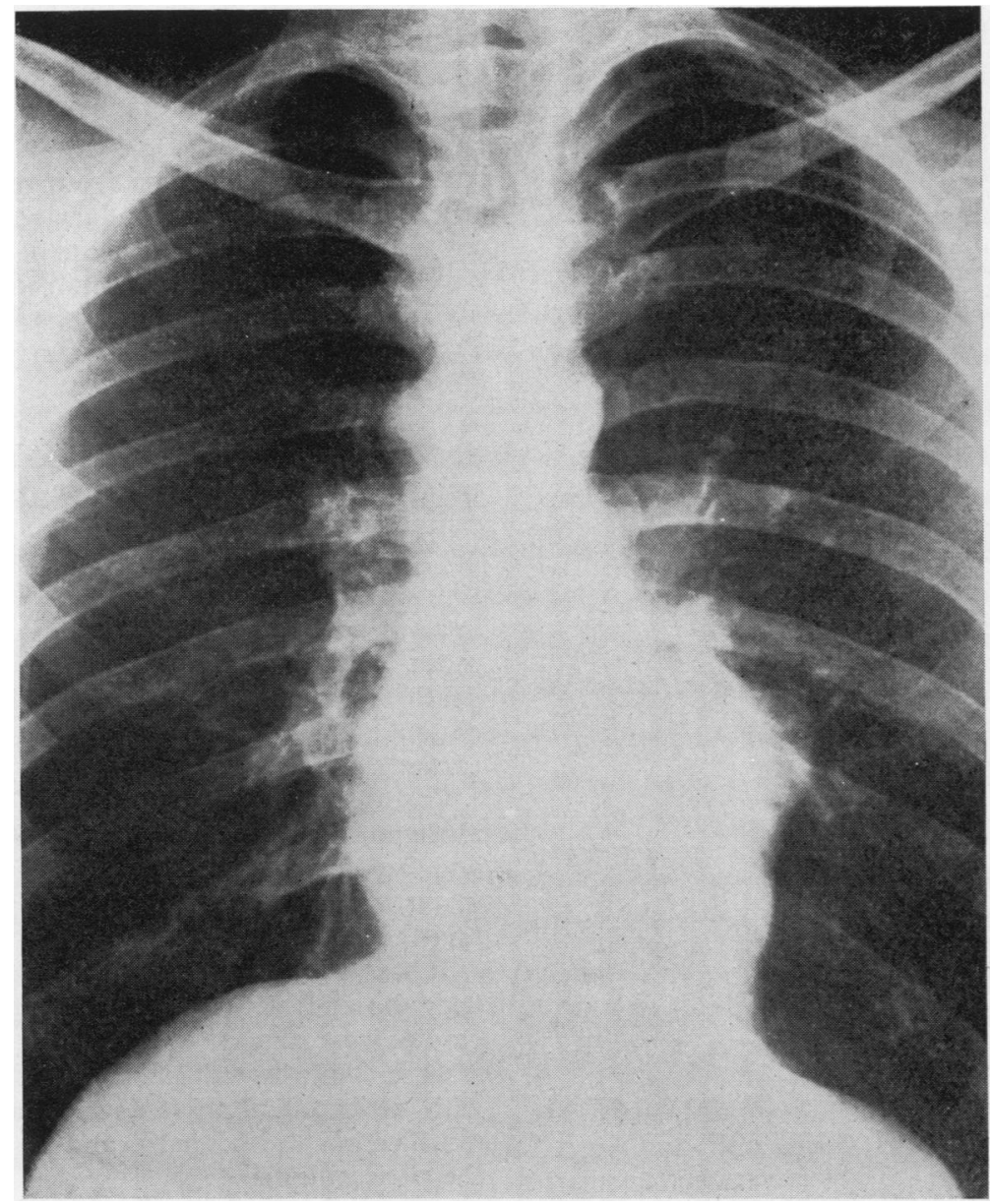

FIG. 7. Case 2. The rounded lesion in the right mediastinum at the level of the neck of the sixth rib.

showed a slightly changed pattern possibly due to the previous operation.

A right antero-lateral thoracotomy was performed on 18 July 1962 . No lesion was found in the pericardium on the right side but a mass was palpable under the superior vena cava near its junction with the azygous vein. The latter was divided and the superior vena cava drawn forwards. The tumour was about $2 \frac{1}{2} \mathrm{~cm}$. in diameter and was found to be continuous with the aorta.

The aorta was mobilized proximal and distal to the mass, and rubber ligatures were passed around the aorta. The connective tissue over the cyst was then opened and the cyst immediately burst. All debris was sucked and mopped out and the laminated membrane removed. The inner layer of the adventitia contained a small area which was translucent and appeared to be a second small cyst. A needle was inserted into this, but it then became apparent that this cyst was actually the lumen of the aorta, and the medial layer of adventitia of the cyst was in fact the intima of the aorta. As soon as the needle was withdrawn the intima partly split and the snares around the aorta were tightened for short periods to allow sutures to be placed without great tension and subsequent tearing. Three periods of occlusion of a maximum duration of 50 seconds were required to control the bleeding. Excess media and adventitia was then removed and sewn over a small pledget of 'oxicel' gauze, thus obtaining haemostasis (Fig. 8).

The right chest was then closed in layers with intercostal drainage to an underwater seal.

The post-operative course was uneventful, and the patient was discharged on 4 August 1962.

\section{DISCUSSION}

The natural history of the cardiac hydatid is of interest, and to find full accounts of this it is 


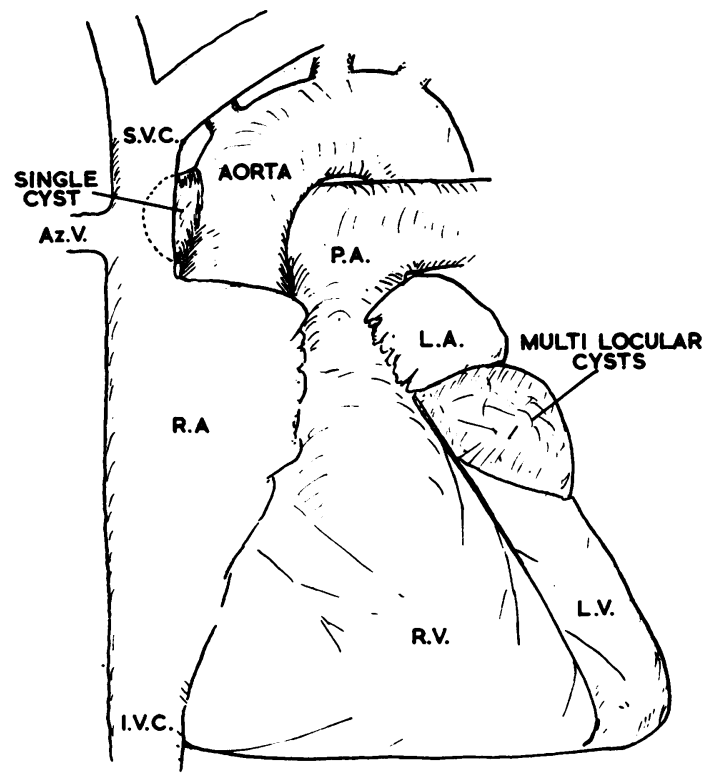

FIG. 8. Case 2. Diagram showing the situation of the two main cystic masses, one in the left atrioventricular groove and the other in the right side of the ascending aorta. $S . V . C .=$ superior vena cava; $A z . V .=$ azygos vein; $P . A .=$ pulmonary artery; L.A.=left atrium; $R . A .=$ right atrium; L.V. = left ventricle; $R . V .=$ right ventricle; I.V.C. = inferior vena cava.

necessary to go back to the original works of Dévé $(1915$; 1916a, b, c) and, later, of Dew (1928). It is from their work that I take this summary.

Hydatid cysts of the heart are usually primary, and these primary cysts are solitary. If multiple cysts are found then they are secondary after rupture.

The cyst may die and become converted into an inspissated mass. Usually, however, spontaneous rupture occurs into the cavity of the heart or into the pericardial sac.

Dévé (1916a) recorded 11 cases of rupture into the left side of the heart followed by secondary cysts in various organs throughout the body, and, of these, $55 \%$ occurred in the brain.

With cysts in the left side of the heart death may occur from rupture of the ventricle or from intracardiac rupture of the cyst leading to cerebral embolism or anaphylactic shock.

The sequence of events in a typical cardiac hydatid is as follows:

FIRST STAGE This lasts from one to five years, during which a primary simple cyst exists in the heart muscle.
SECOND STAGE The cyst ruptures into the pericardium, or more commonly into the ventricle or atrium.

THIRD STAGE This lasts from one to five years, after which multiple secondary pericardial hydatid cysts, or multiple hydatid cysts of the brain, lungs, or elsewhere in the body, begin to grow.

There is reformation of the primary cardiac cyst with daughter cysts, or rarely involution and fibrosis.

FOURTH STAGE The clinical state now depends $\stackrel{\text { N }}{-}$ upon the presence of multiple systemic and $\stackrel{G}{-}$ pulmonary cysts.

FIFTH STAGE There is a second intraventricular or intra-atrial rupture of a secondary pericardial, or $\frac{0}{3}$ more commonly intramural, cyst with sudden $\mathcal{}$ death from anaphylaxis or massive embolism of $\vec{\varphi}$ daughter cysts. The two cases here illustrate some $\stackrel{\oplus}{\perp}$ earlier stages of the disease.

Case 1 had the calcified shadow in the heart representing the primary cyst which had ruptured and become inspissated while multiple secondary metastatic cysts developed in the peritoneal cavity and liver.

It was presumed that the liver cyst was secon- $\overrightarrow{\overrightarrow{0}}$ dary because it was not calcified, whereas the cardiac cyst was.

Case 2 illustrated leaking of the primary cyst with urticarial attacks, development of daughter $\overrightarrow{0}$ cysts within the primary, and metastatic cysts in the pericardium.

SIGNS AND SYMPTOMS Great variation occurs in the presenting sign or symptom. However, the 3 latency of the disease should not be forgotten.o There is often no interference with heart action? and the E.C.G. may be normal. Papo and Savice (1962) laid stress on the changes they had found in their two cases, and Dighiero, Canabal, Aguirre, $N$ Hagan, and Horjales (1958) also considered these N changes important. Of the two cases reported, oneN had changes suggesting a lesion in the anterior ${ }^{\omega}$ wall of the heart and the other had a normal E.C.G. until operation.

The history of repeated urticaria in case $2, \mathbb{D}$ although suggestive of hydatid disease, does not ${ }^{+}$ necessarily incriminate the heart as the site of the lesion.

The increasing use of mass chest radiography may reveal more of these lesions.

Most of the pulmonary hydatids that come to the Royal Hobart Hospital have been diagnosed 
TABLE I

AGE AND SEX OF PATIENTS WITH CARDIAC HYDATIDS SINCE 1922

\begin{tabular}{c|c|c|c}
\hline Age (yr.) & Male & Female & Total \\
\hline $0-9$ & 0 & 0 & 0 \\
$10-19$ & 2 & 3 & 5 \\
$20-29$ & 5 & 4 & 9 \\
$30-39$ & 7 & 5 & 12 \\
$40-49$ & 1 & 6 & 7 \\
$50-59$ & 2 & 2 & 4 \\
$60-69$ & 2 & 1 & 3 \\
$70-79$ & 0 & 1 & 0 \\
$80-$ & 0 & 0 & 41 \\
\hline Total & $\ldots$ & 22 & 7 \\
Age and sex un- & 19 & & 48 \\
known & & & \\
\hline
\end{tabular}

at mass radiography, which is compulsory for all adults in the state of Tasmania.

Dévé (1916b) believes that the primary infestation occurs in childhood, and this may be so for, of 48 cases so far treated surgically, 26 are under the age of 40 and 14 are under the age of 30 years, but to correlate this with the natural history one would expect those in the older age groups to have been infested in adult life (see Table I).

Either the cyst must remain latent in the myocardium longer than was thought, or infestation must on some occasions occur later in life. Probably both are true. The insidiousness of the process may be emphasized by the fact that before 1920 no cases had been diagnosed ante mortem; the first case was that reported by Marten and de Crespigny in 1921.

The anatomical site of the main cardiac hydatid cyst is most commonly in the left ventricle: Table II shows the site of 48 cardiac hydatid cysts reported to date ; 34 have been somewhere in the left ventricular muscle. This is directly opposed to the early view, as stated by Peters, Dexter, and Weiss (1945) and Windsor (1954), but is in accordance with Dévé's figures (1916c). This fact is probably due to the greater vascular supply of the left ventricle.

T A B L E I I

ANATOMICAL SITE OF CARDIOVASCULAR HYDATIDS

\begin{tabular}{|c|c|c|c|c|}
\hline \multicolumn{4}{|c|}{ Site } & \multirow[b]{2}{*}{$\begin{array}{r}\text { No. } \\
29 \\
2 \\
5 \\
1 \\
2 \\
2 \\
4 \\
2 \\
1\end{array}$} \\
\hline $\begin{array}{l}\text { Left ventricle } \\
\text { Right ventricle } \\
\text { Left atrioventricular } \\
\text { Both ventricles } \\
\text { Right atrium } \\
\text { Left atrium . } \\
\text { Pericardium only } \\
\text { Site unspecified } \\
\text { Aorta and left atrio }\end{array}$ & $\begin{array}{ll}\ldots & \ldots \\
\cdots & \ldots \\
\text { ir } & \text { groove } \\
\ldots & \ldots \\
\ldots & \ldots \\
\cdots & \ldots \\
\ldots & \cdots \\
\cdots & \cdots \\
\text { ventricul }\end{array}$ & $\begin{array}{l}\cdots \\
\cdots \\
\cdots \\
\cdots \\
\cdots \\
\cdots \\
\text { roove }\end{array}$ & $\begin{array}{l}\cdots \\
\cdots \\
\cdots \\
\cdots \\
\cdots \\
\cdots \\
\cdots\end{array}$ & \\
\hline & Total & $\ldots$ & $\ldots$ & 48 \\
\hline
\end{tabular}

A search of the literature has failed to produce a previous case report of a hydatid cyst within the wall of the aorta. The cyst in our patient was situated between the media and the intima, presumably carried to the aorta by the vasa vasorum.

Figure 9 shows its relation to the intima and the reason why the inner layer split when a needle was passed through it.

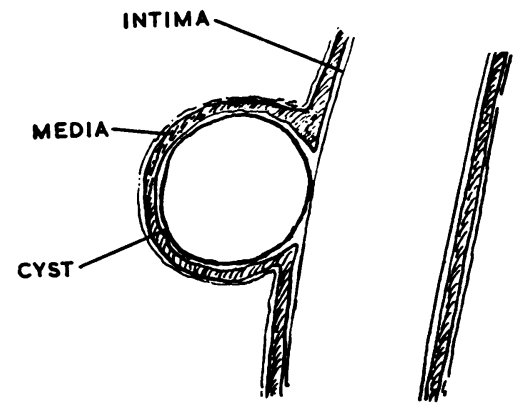

FIG. 9. Case 1. A diagram showing the relation of the aortic cyst to the intima and media.

The diagnosis is made according to the history and the radiological findings. Of the ancillary aids, the E.C.G. may be helpful, as has already been discussed. Angiocardiography and cardiac catheterization may be helpful in differentiating from aneurysms or other cardiovascular lesions (Papo and Savić, 1962), but in general the diagnosis can be made without these aids.

Once the diagnosis has been made, the correct course is surgical intervention. With modern techniques of anaesthesia and surgery, the risk to the patient is less than leaving the cyst in situ, for the incidence of death from rupture of a cardiac hydatid is very high.

The first attempt at operative treatment of this condition was made in Australia in 1921 by Marten and de Crespigny, which unfortunately resulted in the death of the patient. The first successful removal was reported by Long, also in Australia, in 1932. Since then there have been operations on 48 patients with successful results in 42 , death in four cases, and an unknown outcome in two cases.

This mortality rate compares favourably with that of other cardiac operations for conditions where conservative or medical treatment only carries a brighter prognosis than it does for a cardiac hydatid.

The operative approach must be dictated by the site of the lesion. In case 1 , an antero-lateral thoracotomy through the lower border of the fifth 
rib gave an excellent exposure without any need to divide the sternum. In case 2 , because the lesion was more posteriorly placed, a posterolateral thoracotomy was used, again through the fifth rib, and again a very adequate exposure was obtained without having to divide the sternum.

On the right side an antero-lateral thoracotomy was used, and this made the operative procedure rather more difficult than a postero-lateral incision. During the operative procedure the superior vena cava partially obstructed the view of the area under dissection.

Here is a word of warning for those who are dealing with this lesion; beware of the apparent further cysts deep to the main one removed. In each case needling this cyst has caused considerable vascular difficulty and resulted in unnecessary blood loss for the patient. A pause and careful assessment of the local anatomy may supply the surgeon with enough information to prevent such an occurrence.

Operation was performed on both patients at normal temperature and without any ancillary aids, such as cardiopulmonary by-pass. It was possible to deal adequately with all the cysts found, and I am of the opinion that to use such equipment would make a simple operation unnecessarily complicated.

If the aortic hydatid cyst had involved the aortic valve, then it might have been necessary to use cardiopulmonary by-pass, but there would have been clinical evidence of this aortic valvular lesion pre-operatively.

The three short periods of aortic occlusion necessary to obtain haemostasis were tolerated by the patient without apparent ill effect. $\mathrm{He}$ was conscious before leaving the theatre, out of bed the day after operation, and ready to go back to work in his orchard after one week.

\section{SUMMARY}

Two cases of cardiac and aortic hydatid cysts are described, and a short discussion follows on the natural history of cardiac hydatids, together with some of the problems of diagnosis and operative techniques.

I wish to thank the librarians of the Gordon Craig Library of the Royal Australian College of Surgeons and of the library of the University of Tasmania for their help with references; Dr. C. Duncan for the photography and for producing the plates; and Mr. P. Braithwaite, senior thoracic surgeon at the Royal
Hobart Hospital, for his unfailing help and advice and for allowing me to operate on these two patients.

\section{BIBLIOGRAPHY}

Amargos, A., Armand Ugon, V., Larghero, P., and Di Bello, R. (1947). Tres casos de equinococosis cardiopericardica operados. Arch. urug. Med., $30,483$.

Attwood, C. J., Sargent, W. H., and Taylor, F. (1941). Echinococcus cyst of the heart. Report of a case. Ann. intern. Med., 15, 1109.

Barrett, N. R. (1960). The anatomy and the pathology of multiple hydatid cysts in the thorax. Ann. roy. Coll. Surg., Engl., 26, 362. Barclay, S. (1954). Cardiac hydatid cyst. Report of a case. N.Z. med. J., 53, 605

Belton, C. H. (1956). Report on a case of multiple hydatid cysts, hepatic, pulmonary and endocardial. Ibid., 55, 62 .

Blakely, E. R., and Reid, J. D. (1951). Hydatid disease: Report of an unusual case. Ibid., 50,44

Canabal, E. J., Aguirre, C. V., Dighiero, J., Purcallas, J., Baldomir, J. M., and Suzacq, C. V. (1955). Echinococcus disease of the left $N$ ventricle: A clinical, radiologic and electrocardiographic study. Circulation, 12, 520

d'Abreu, A. L. (1950). The removal of a hydatid cyst from the wall of the left ventricle. Thorax, $5,362$.

Demirleau, J., and Cohen, H.H.'(1956). Quatre nouvelles observations de kyste hydatique du coeur. Poumon, 12, 941.

Dévé, F (1915). Sur l'échinococcose secondaire du péricarde. $C . R$ Soc. Biol. (Paris), 78, 734.

- $(1916 a)$. La rupture intérative des kystes hydatiques du coeur. Ibid., $79,514$.

- (1916b). L'échinococcose chez l'enfant. Intérêt dotrinal de son étude. Ibid., 79, 911.

(1916c). L'échinococcose secondaire locale du coeur. Ibid., 79, 829.

Dew, H. R. (1928). Hydatid Disease. Australasian Medical Publishing Company, Sydney.

Dighiero, J., Canabal, E. J., Aguirre, C. V., Hazan, J., and Horjales, J. O. (1958). Echinococcus disease of the heart. Circulation, 17, 127.

Di Bello, R., Stanham, J., Rubio, R., and Muxi, F. (1962). Hydatid cyst of the left ventricular wall with rupture into the intrapericardial space. J. thorac. Surg., 44, 268.

Henry, E. (1958). Kyste hydatique du coeur. Deux nouveaux cas $\mathbb{D}$ diagnostiqués et opérés. Mém. Acad. Chir., 84, 153.

Houel, J. (1956). Kyste hydatique du ventricule gauche. $\AA$ propos $\overrightarrow{\vec{D}}$ de deux observations. Presse méd., 64, 2184.

Jidejian, Y. (1957). Collective review of hydatid disease. J. int. Coll. Surg., 28, 125.

Kurban, A. K., Shafik, A. I., Attar, S. A., and Dragatsi, G. A. (1953). Echinococcosis of the heart. Amer. Heart J., 46, 764.

Lacroix, A. C., and Houel, J. (1957). Un cas de kyste hydatique du coeur. Arch. int. Hidatid., 16, 413.

Larghero, P., Di Bello, R., and Victorica, A. (1950). Pericarditis constrictiva hidática. Ibid., 11, 346.

Long, W. J. (1932). Hydatid cyst in the left ventricular wall of the heart. Med. J. Aust., 2, 701.

Marten, R. H., and de Crespigny, C. T. C. (1921). Notes on a case of hydatid of the heart. Ibid., 1, 287.

Michaud, M., Saubier, E., Maret, G., Viard, H., Termet, H., and Gravier, J. (1959). Un cas de kyste hydatique du coeur opéré et $O$ guóri. Lyon chir., 55, 768.

Mills, H. W. (1922). Hydatid cysts of the heart, with report of case. Surg. Gvnec. Obstet., 35, 455.

Molloy, P. J. (1955). Pericardial hydatid cysts. N.Z. med. J., 54, 267.

Nicks, R. (1961). Sydney, Personal Communication.

Papo, I., and Savić, S. (1962). Hydatid disease of the heart; a reporto on two cases treated surgically. Brit. J. Surg., 49, 598.

Peters, J. H., Dexter, L., and Weiss, S. (1945). Clinical and theoretical considerations of involvement of the left side of the heart with $\mathrm{N}$ echinococcal cysts. Amer. Heart J., 29, 143.

Perez Fontana, V., and Sapriza, J. P. (1953). Quiste hidatico hialino N del ventriculo izquerdo. Arch. int. Hidatid., 13, 157.

Pullar, T. H., and North, J. H. (1939). Ruptured hydatid cyst of the heart. Aust. N.Z. J. Surg., 8, 399.

Rakower, J., and Milwidsky, H. (1960). Primary mediastinal echinococcosis. Amer. J. Med., 29, 73.

Robertson, G. H. (1952). Hydatid cyst of the heart simulating ance aneurysm. A correction. N.Z. med. J., 51, 388.

Romanoff, H., and Milwidsky, H. (1962). Primary echinococcosis of $\bar{Q}$ the heart cured by operation. J. thorac. Surg., 43, 677 .

Sbarounis, N. (1957). Sur un cas opéré de kyste hydatique du coeur. Arch. int. Hidatid., 16, 427.

Starr, K. W. (1949). Hydatid cyst of pericardium. Aust. N.Z. J. Surg., O

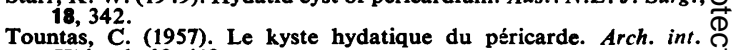

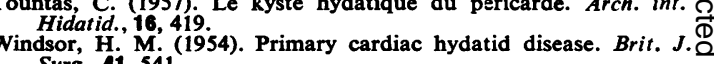
Surg., 41, 541. 